\title{
Isoflavone Content and Composition in Soybean
}

\author{
Vesna Tepavčević, Jelena Cvejić, Mihalj Poša and Jovan Popović \\ University of Novi Sad \\ Serbia
}

\section{Introduction}

Soybean seed has been used in a diet of East-Asian population for centuries. Western population has raised interest in this item after numerous epidemiological and clinical studies have showed that, due to the large consumption of soybean, there is less incidence of cardio-vascular disease, osteoporosis, and certain types of cancer in Japan and China, in comparison to western countries (Scheiber et al., 2001; Chiechi et al., 2002; Potter et al., 1998; Barnes et al, 1994; Adlercreutz \& Mazur 1997; Sarkar \& Li, 2003; Lee et al., 2003b; Moriguchi et al., 2004; Ikeda et al., 2006; Wu et al., 2008).

Several classes of biologically active compounds are found in soybean, but it is considered that isoflavones are most responsible for its favourable influence on health (Crouse et al., 1999). Isoflavones are natural occurring substances, present in some plants, which are structurally similar to estrogens and can exibit weak estrogen-like effects. For this reason, they are classified as phytoestrogens: plant-derived compounds with activity similar to estrogens. Isoflavones are not widespread in nature and can be found almost exclusively in the plants of the Leguminosae family (Anderson \& Wolf, 1995; Philips et al., 2002; Romani et al., 2003). In that sence soybean is one of few isoflavone sources in human nutrition, which explains its wide use through different food products and isoflavone-rich dietary supplements.

\subsection{Chemical structures of isoflavones}

Isoflavones are polyphenolic compounds which exist in twelve differents chemical forms (Lee et al., 2004). Daidzein, glycitein and genistein are the aglycone forms of isoflavones (Fig.1). In conjuction with sugars, they build the $\beta$-glucosides (daidzin, glycitin<smiles>[R]c1c(O)cc2occ(-c3ccc(O)cc3)c(=O)c2c1[R]</smiles>

\begin{tabular}{lcc} 
Name & $\mathrm{R} 1$ & $\mathrm{R} 2$ \\
\hline Daidzein & $-\mathrm{H}$ & $-\mathrm{H}$ \\
Glycitein & $-\mathrm{H}$ & $-\mathrm{OCH}_{3}$ \\
Genistein & $-\mathrm{OH}$ & $-\mathrm{H}$
\end{tabular}

Fig. 1. Chemical structures of aglycone forms of isoflavones 
and genistin), the 6"-O-malonyl glucosides (malonyl daidzin, malonyl glycitin, and malonyl genistin) and the 6"-O-acetyl glucosides (acetyl daidzin, acetyl glycitin, and acetyl genistin). The aglycone structures can be found in very small amounts in soybean, while the glycoside forms are dominant. However, isoflavones in glycoside forms are inactive, because hydrolysis and the release of the aglycone component are essential for the absorption of isoflavones in the digestive tract (Day et al., 1998). For this reason aglycones are considered to be biologically active forms of isoflavones.

\subsection{Biological activity of isoflavones}

Isoflavones perform most of their biological effects through modulation of estrogenic receptors (ER), as a result of their structural similarity with human estrogens (Cederroth \& Nef, 2009). By comparing the chemical structures of genistein and estradiol (Fig.2) it can be noticed that the genistein rings $\mathrm{A}$ and $\mathrm{C}$ are similar to the estradiol rings $\mathrm{A}$ and $\mathrm{B}$ and the distance between hydroxyl groups is almost identical in both molecules.

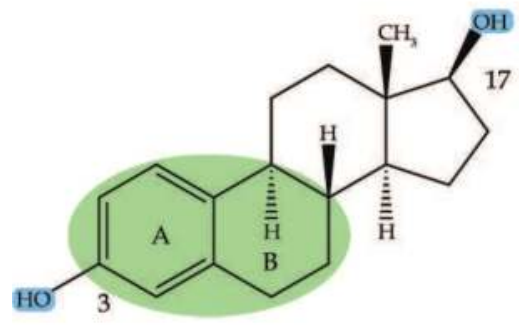

Estradiol

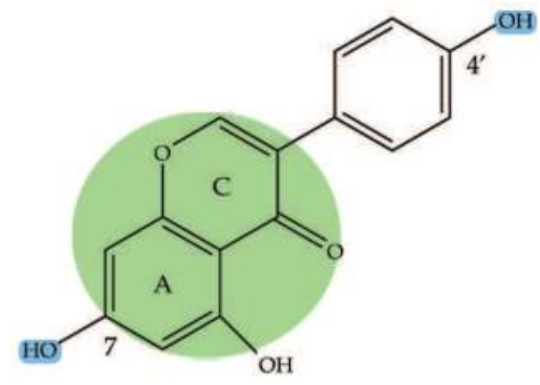

Genistein

Fig. 2. Structures of estradiol and genistein

The isoflavone affinity towards estrogenic receptors results in numerous effects on estrogenregulated systems, including cardiovascular, metabolic, reproductive, skeleton, and central nervous system. A significant characteristic of isoflavones is their capacity to bond to both subtypes of estrogenic receptors (ERa and ER $\beta$ ), but mainly to $\beta$ receptors. Such specific affinity towards estrogenic receptors allows them to perform estrogenic and anti-estrogenic effects, depending on the type of the tissue and the endogenous estrogen levels (Kupier et al., 1997; Kupier et al., 1998). Tissue-selective activity of isoflavones is important because anti-estrogenic effects in reproductive tissue can decrease the risk of hormone-dependent cancers (breast, uterus, and prostate cancer), while estrogenic effects in other tissues can impact preventively towards osteoporosis and hypercholesterolemia. In comparison with physiological estrogens, isoflavones are very weak estrogens which, on the molar basis, have from $10^{-2}$ to $10^{-4}$ activities of $17 \beta$-estradiol (Biggers \& Curnow, 1954; Bickoff, 1962). Genistein has ten times higher estrogenic activity comparing to daidzein (Branham et al., 2002; Diel et al., 2000; Diel et al., 2004), whereas glycitein has the highest estrogenic potential in vivo (Song et al., 1999). Genistein and glycitein can be biodegraded into metabolites with no estrogenic activity (Cassidy et al., 2000; Simons et al., 2005), while daidzein can be metabolised into equol, which has higher estrogenic potential than daidzein (Setchell et al., 2002). 
Soy isoflavones and their metabolites can also exhibit the biological activity independent from their interactions with estrogenic receptors (Barnes et al., 2000). They inhibit the synthesis and activity of the particular enzymes included in estrogenic metabolism, as well as the activity of tyrosine kinase (Whitehead et al., 2002; Akiyama et al., 1987). Besides, isoflavones can act as antioxidants (Ruiz-Larrea et al., 1997; Wiseman et al., 2000; Djuric et al., 2001, Malencic et al., 2008).

\subsection{Dietary supplements on the basis of soyben isoflavones}

Soy isoflavones, among other phytoestrogens, are used as the alternative to estrogen hormone replacement therapy in menopause. Concerns about potential side effects of hormone therapy have resulted in the increased interest for the usage of soy-based dietary supplements (Nelson et al., 2006). However, the efficiency of these supplements can vary significantly as a result of uneven quality of the preparations, differences in populations and individual differences of patients. For example, the isoflavone content in soy-based dietary supplements can vary among producers, and even among series of the same producer (Cesar et al., 2006).

Labels of soy-based dietary supplements mainly inform about the total isoflavone content, while the information on the individual isoflavone contents is not provided. Nevertheless, biological potential of preparations with the same total isoflavone content can be different due to the variations of isoflavone composition in primary raw material (soybean seed) (Ceran et al., 2007; Tepavcevic et al., 2009). Thus, it is exceptionally important to determine individual isoflavone contents in the soybean seed. Exploring of the factors which can influence the isoflavone content and composition in soybean enables the selection of the raw material which potentially has the most beneficial effect on health.

\subsection{Factors that influence the isoflavone content and composition in soybean seed}

The total isoflavone content in soybean seeds ranges from $0.05 \%$ to $0.50 \%$ of dry material. Distribution of individual isoflavones within these values can vary significantly, although it is known that daidzein with its conjugates and genistein with its conjugates are present in nearly equal amounts in soybeans, whereas glycitein and its conjugates are present in lesser amounts (Lee et al., 2004). Variations in content and composition of the soybean isoflavones occur as a consequence of different factors, among which the most examined are the genotype of the seed, as well as the year and location of seeding.

\subsubsection{Genotype}

According to the previous reports, genotype significantly influences the content and composition of isoflavones in soybean seed (Wang \& Murphy, 1994; Hoeck et al., 2000; Lee et al., 2003c). Thus, the determination of isoflavone profiles in different soybean varieties has become the subject of numerous studies, with the aim of selecting genotypes that have better healthpromoting characteristics. Majority of these reports come from the countries which are the largest exporters of soybean at the world market, such as the USA, Brazil, Argentina, China, and India.

American soybean varieties have high total isoflavone levels, with genistein and its conjugates as predominant isoflavone forms. $\mathrm{Xu}$ and Chang (2008) reported that the total isoflavone content in thirty soybean genotypes (from the North Dakota - Minnesota region) ranged between 1.18 and $2.86 \mathrm{mg} / \mathrm{g}$ of the seed, out of which $69 \%$ were genistein and its 
conjugates. Another study, conducted on eight American soybean genotypes, showed that the content of total isoflavones varied from 2.05 to $4.22 \mathrm{mg} / \mathrm{g}$ of the seed, with malonyl genistin as the most abundant component, comprising $42 \%$ of the total isoflavone content, in the average (Wang \& Murphy, 1994). Nine American genotypes form Virginia (Chung et al., 2008) had the total isoflavone content ranging from 2.50 to $3.20 \mathrm{mg} / \mathrm{g}$ of the seed, out of witch $75-84 \%$ was malonyl genistin. The study on fifteen Korean soybean varietes showed, however, that the total isoflavone contents in these genotypes were significantly higher than in the seeds from other countries, ranging from 1.88 to $9.49 \mathrm{mg} / \mathrm{g}$ of the seed (Lee et al., 2003a). Analysis of individual isoflavones in soybeans from China and Korea demonstrated that Chinese genotype contained higher isoflavone amounts than Korean genotype (Lee et al., 2007). Brazilian soybean genotypes had considerably lower isoflavone concentrations in comparison with American and Korean genotypes, according to the study by Genovese and collaborators (2005). They reported that total isoflavone content in thirteen Brazilian genotypes ranged between 0.57 and $1.88 \mathrm{mg} / \mathrm{g}$ of the seed. Low content of total isoflavones in Brazilian genotypes were found by Ribeiro and collaborators (2007), as well. In eighteen different soybean genotypes, they found the total isoflavone levels ranging from 0.9 to 1.21 $\mathrm{mg} / \mathrm{g}$ of the seed. Genotype from Ecuador had $0.68 \mathrm{mg}$ of total isoflavones per $\mathrm{g}$ of the seed, which is in the range of Brazilian genotypes, but far below isoflavone content in American and Korean genotypes (Genovese et al., 2006). The average total isoflavone content in Indian seeds, according to the study by Devi and collaborators (2009), was $0.76 \mathrm{mg} / \mathrm{g}$ of the seed.

The wide range of total isoflavone values, from $0.68 \mathrm{mg} / \mathrm{g}$ in Ecuador seed up to $9.49 \mathrm{mg} / \mathrm{g}$ in Korean seed are due to the significant differences in explored soybean genotypes, but also may reflect the diverse conditions of seeding, as well as the variations in methods of isoflavone determination between the studies.

\subsubsection{The year and location of seeding}

The year and location of soybean seeding can considerably influence the isoflavone content in the seed, while their influence on the isoflavone composition is less distinctive. According to Wang and Murphy (1994), the year of seeding substantially influenced the total and individual isoflavone contents, but not the isoflavone distribution in soybeans. In the same study, the seeding location did not have a significant influence either on the total and individual isoflavone contents, or their distribution. The study by Hoeck and collaborators (2000), however, showed that the location of seeding, beside the genotype of seed and the year of seeding, can impact the isoflavone contents in soybean. Lee and collaborators (2003a) concluded that the seeding year affects isoflavone contents more than the location or genotype. They reported that the range of total isoflavone contents in fifteen soybean varieties varied from 2.20 to $6.45 \mathrm{mg} / \mathrm{g}$ in 1998, from 3.19 to $9.50 \mathrm{mg} / \mathrm{g}$ in 1999 and from 2.93 to $4.83 \mathrm{mg} / \mathrm{g}$ in 2000. Tsukamoto and collaborators (1995) suggested that part of the effects attributed to years and locations in research studies may reflect differences in the temperatures that occur during seed development, as a result of the date of planting. Hence, it can be concluded that the diversity of isoflavone contents depend on unknown climatic and environmental factors and genetic variation.

\section{Our works}

Throughout our research, we have analysed the content and composition of isoflavone in domestic and introduced soybean genotypes grown in Vojvodina, the northern region of 
Serbia. Previous reports about isoflavone content in soybean seeds grown in Vojvodina have not been found, as this region (belonging to Central Europe) is not generally accepted for ecological surroundings of soy. Our research (Cvejic et al., 2009; Tepavcevic et al., 2010) involved sixty different genotypes of soybean grown on the experimental fields of the Institute of Field and Vegetable Crops in Rimski Šančevi, Novi Sad, during 2004, 2005, and 2006 (Table 1).

\begin{tabular}{|c|c|c|}
\hline 2004 & 2005 & 2006 \\
\hline 1. LN92-7369 & 21. Alisa $\mathrm{x}$ Lori & 41. Černovitska 9 \\
\hline 2. $1581 / 99$ & 22. Alisa $\times$ Linda & 42. Veselovska \\
\hline 3. 1511 & 23. Alisa $\times$ Meli & 43. Amurska \\
\hline $4.1499 / 99$ & 24. Alisa $\times$ Tara & 44. Čerivnica stepu \\
\hline 5. Lori & 25. Alisa $\times 1499$ & 45. Mandzurska \\
\hline 6. Linda & 26. Alisa $\times$ BL-8 & 46. Venera \\
\hline 7. Balkan & 27. Alisa $\times$ Sava & 47. Valjevka \\
\hline 8. BL-8 & 28. Alisa $\times$ Venera & 48. Ana \\
\hline 9. Alisa & 29. Alisa $\times$ Morava & 49. NS-L-410015 \\
\hline 10. Tara & 30. Alisa $\times$ Balkan & 50. Galina \\
\hline 11. Meli & 31. Balkan $\times$ Sava & 51. Sargent \\
\hline 12. Sava & 32. Balkan $x$ Venera & 52. MN 1801 \\
\hline 13. Venera & $33.1499 \times$ Sava & 53. Ne1900 \\
\hline 14. Morava & 34. Sava $x$ Venera & 54. Barnes \\
\hline 15. LN92-1581 x 1581/99 & 35. Venera $x$ Morava & 55. MN 0901 \\
\hline $16.1499 / 99 \times 1581 / 99$ & 36. (LN92 x 1581) x (1499 × 1518) & 56. Chang Nong 5 \\
\hline $17.1499 / 99 \times 151$ & 37. $(1499 \times 1511) \times($ Lori $\times$ LN92 $)$ & 57. JJ 96021 \\
\hline 18. Lori $x$ LN92-158 & 38. (Linda $\times$ LN92) $\times($ Balkan $\times$ BL-8) & 58. Ba 28 \\
\hline 19. Linda $x$ LN92-158 & 39. Balkan x (Balkan $\times$ BL-8) & 59. NM 97002/1 \\
\hline 20. Balkan x BL-8 & 40. BL-8 x (Balkan $\times$ BL-8) & 60. Jilin Provinca \\
\hline
\end{tabular}

Table 1. Examined soybean genotypes

The sample from 2004 included twenty genotypes, among which fourteen were the already cultivated varieties, and the remaining six were their F1 hybrids. Seeds from 2005 (twenty different genotypes) represented F1 hybrids of the genotypes from 2004. Within the sample from 2006, twenty genotypes of different origin (Russia, the USA, China and Serbia) were analysed. The presented sample enabled analysis of the influence of particular factors on isoflavone content in soybean, such as hybridisation, seeding year and the origin of seed. The obtained results were also important for comparison with the isoflavone content and composition of soybeans grown in other regions.

The analysis of soybeans grown in 2004 suggested that the total isoflavone values of all the twenty genotypes were considerably higher than some reported earlier (Cvejic et al., 2009). The total phytoestrogen concentration was found to be between 2.24 and $3.79 \mathrm{mg} / \mathrm{g}$ dry bean weight. The average amount of daidzein and its conjugates in the analysed cultivars was the highest $(45.6 \%)$, followed by genisteins $(39.3 \%)$, while glyciteins were present in the least amount in all analysed samples (15.0\%). Low percentage of genistein components in the analysed genotypes, in comparison with the genotypes examined in the USA and Korea (Wang \& Murphy, 1994; Hoeck et al., Lee et al, 2003c) reflects the potentially less biological 
quality of genotypes grown in this region. However, the analysis of Cvejic and collaborators showed that, considering isoflavone content and distribution, some specific genotypes could be distinguished. There was a group of genotypes, which exhibited a significantly higher content of isoflavones, in comparison to others. A group of genotypes with higher content of genisteins, biologically the most active phytoestrogens in soy, could also be clearly distinguished. The results suggested that analysed genotypes, especially 1581/99, BL-8 and Meli might be of interest to producers, plant breeders and phytopharmacists due to their elevated content of phytoestrogens.

Hybrid genotypes assayed in 2005 had concentration of total isoflavones from 1.56 to 3.66 $\mathrm{mg} / \mathrm{g}$ of dried bean (unpublished results). Daidzein and its conjugates were the most abundant isoflavone forms $(50.8 \%)$, followed by genisteins $(39.5 \%)$, while glyciteins were less abundant $(9.7 \%)$. The evaluation of the resemblance between hybrids and their parents was conducted according to the samples 21-30 (Table 1). These hybrids had one mutual parent (Alisa), while they differed in the other parent. There was a high correlation $(\mathrm{r}=0.9)$ between parents and corresponding hybrids, considering the values of their total isoflavone content (Fig. 3), content of daidzeins and content of genisteins. These results reflected the feasibility of breeding soybean genotypes with favourable characteristics and better healthpromoting potential.

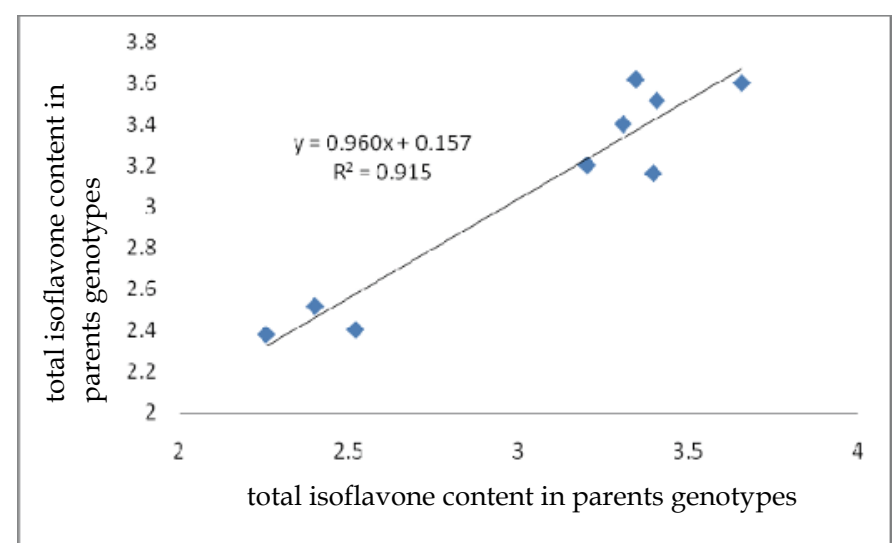

Fig. 3. Correlation of total isoflavone content between parent and hybrid genotypes (unpublished results)

The values of total isoflavone content in the samples from 2006 were between $1.45 \mathrm{mg} / \mathrm{g}$ and $4.59 \mathrm{mg} / \mathrm{g}$ of dry material (Tepavcevic et al, 2010). The amount of daidzein and its conjugates was the highest $(47.2 \%)$, followed by genisteins $(40.2 \%)$ while glyciteins were present in the lowest (12.6\%) amount, considering the average of twenty analysed soybean varieties. There was a statistically significant difference among the examined genotypes in the contents of total isoflavones, daidzeins, glyciteins and genisteins $(\mathrm{p}<0.05)$. On the other side, the groups of genotypes formed on the basis of seed origin (American, Russian, Serbian and Chinese) did not differ significantly. The results suggest that isoflavone composition is a characteristic mainly determined by the genotype and not by the origin of soybean seeds. 


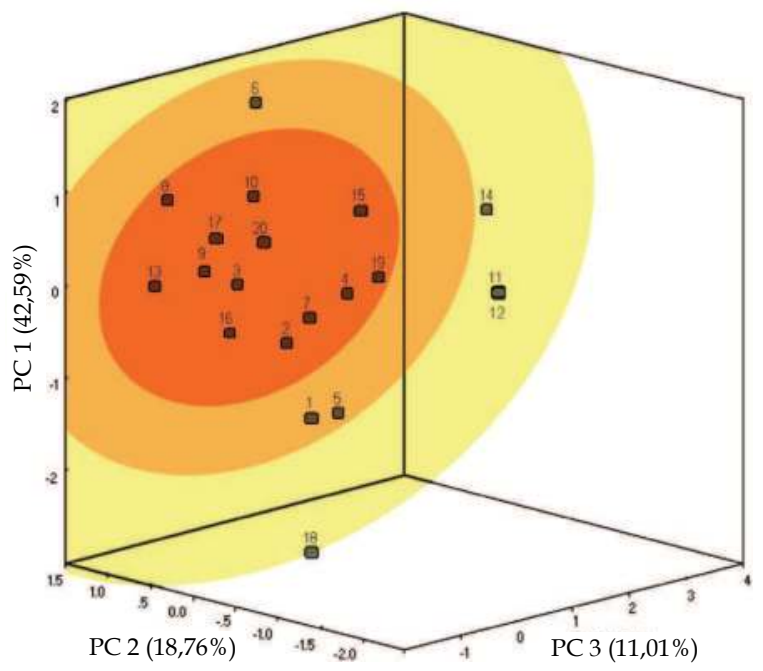

Fig. 4. Variance of cultivars explained by Principle Component Analysis (Tepavcevic et al., 2010).

In the research by Tepavcevic and collaborators (2010), principal component analysis (PCA), as statistical tool, was applied for the interpretation of the results about isoflavone content and composition in soybeans. To the best of author's knowledge, PCA was used in this purpose for the first time. Method of PCA enabled more comprehensive observation of the isoflavone profiles, simultaniously in twenty different genotypes of soy. The data about the content of twelve different isoflavones in the examined soy samples were abstarcted into three principal components which described $72.26 \%$ of total variance of the original data. These three principal components (PC1, PC2, and PC3) have been represented as coordinates of a three dimezional graph within which the samples are allocated according to their features, Fig 4. The resembling samples are grouped together, whereas the samples that are distinct are abstracted from the others in graph. For example, it is noticeable that genotypes 11, 12, 14, and 18 are clearly abstracted from others (numbers 1-20 in Fig.4 correspond to samples 41-60 in Table 1). This distinction is a result of dissimilarity in content and composition of isoflavones in these cultivars, comparing to the others: sample 18 (Ba-28) had a very low content of all isoflavones, and samples 11 (Sargent) and 14 (Barnes) had much higher content of malonyl genistin in relation to the content of malonyl daidzin.

The use of Principal Component Analysis in the research by Tepavcevic and collaborators (2010) enabled selection of genotypes with favourable characteristics, from the sample that contained twenty soybean varietes of different origin. Hence, the same method was applied within this chapter on a larger sample size, which included data on isoflavone contents in sixty previously analysed soybean genotypes (Table 1), with the aim to draw conclusions about factors that influence isoflavone distribution in soybeans.

\section{Methods}

Principal Component Analysis (PCA) is a mathematical procedure which is used to decrease the number of variables (features of the analysed objects), i.e. to decrease the size of data 
matrix X (Brerton, 2003). In chemometrics of medical chemistry it is usual that rows of a matrix represent objects (in this case different genotypes of soy), while columns of the $X$ matrix represent variables (concentartions of twelve different isoflavones). The aim is to group the observed objects by the similarity of variables of the $\mathrm{X}$ matrix, or to group the observed variables by the similarity of objects of the $X$ matrix, and to visualise the mutual similarity of objects or variables. The PCA method gives eigenvectors, which are the vectors of principal components, PC (loadings). Loading vectors of principal components have the dimension that corresponds to the total number of variables of the $X$ matrix, so these vectors determine orientation of the principal component axis in the original space of variables. If the coordinates of the principal components loadings are showed in 2D (first two loadings) or 3D (first three loadings) space, the information about the direction and the strength of mutual correlation between variables can be obtained easily according to the mutual position of variables. Eigenvectors (vectors of principal components, PC) are ordered according to the falling eigenvalues - a part of variation that they explain in the $\mathrm{X}$ matrix. The principal component PC1 explains most of the variation, while PC2 explains most of the variation which has not been explained by PC1. The principal component PC3 explains most of the total variation of the X matrix which has not been explained by PC1 and PC2 (Szepesvári, 2001; Posa, 2010). However, usually the first three principal components explain most of the variation in the $\mathrm{X}$ matrix, so other principal components are not used. According to Wold (1975) principal components with small eigenvalues explain the error of measurement. The product of the data matrix $X$ and the matrix of loading vectors of principal components gives a score matrix of principal components (columns of this matrix are the vectors of the principal components values). In the plane (PC1 and PC2) or in the space (PC1, PC2, and PC3) scores of the principal components are visualised objects (Atanackovic et al., 2009). Similar objects form clusters (groups); the more resembling some objects are the closer they stand in the graph.

\section{Results and discussion}

The Principal Components Analysis method, using cross validation procedure according to Krsanowski, has been applied to the data matrix (Table 2) which is standardised to the unit variance of variables (objects: soybean seeds - 60, variables: isoflavones - 12). Screen test shows that the first two components (PC) are sufficient for modelling the twelve variables, because they explain $68.26 \%$ of the total variance of the original data, Fig.5.

In the plane of PC1 and PC2 loading vectors, the coefficients of the principal components are presented, Fig. 6. Variables $\mathrm{mDI}$, aDI, mGI, GI, GYI, DI, GY, mGY are mostly present in the principal component PC1 (the coefficient of their correlation with PC1 is higher than 0.5). Concerning the fact that PC1 carries $50.83 \%$ of information about the variance of individual isoflavone contents, the above mentioned isoflavones have a crucial role in the defining of isoflavone profile in soybean. On the other hand, variables DE and GE are mostly present in component PC2, whereas variables aGI and aGYI are equally present in both principal components, which reflects minor importance of these isoflavone forms in determination of the isoflavone profile.

In the PC1-PC2 plane (Fig. 6) there are five groups of variables which are significantly correlated in the same direction: (GE, DE), (aGI, aGYI), (mDI, aDI, mGI), (GI, GYI) and (DI, GY, mGY). Their vectors mutually close an angle whose cosinus is close to 1 , providing the ability for each variable within the brackets to be represented by the other from 


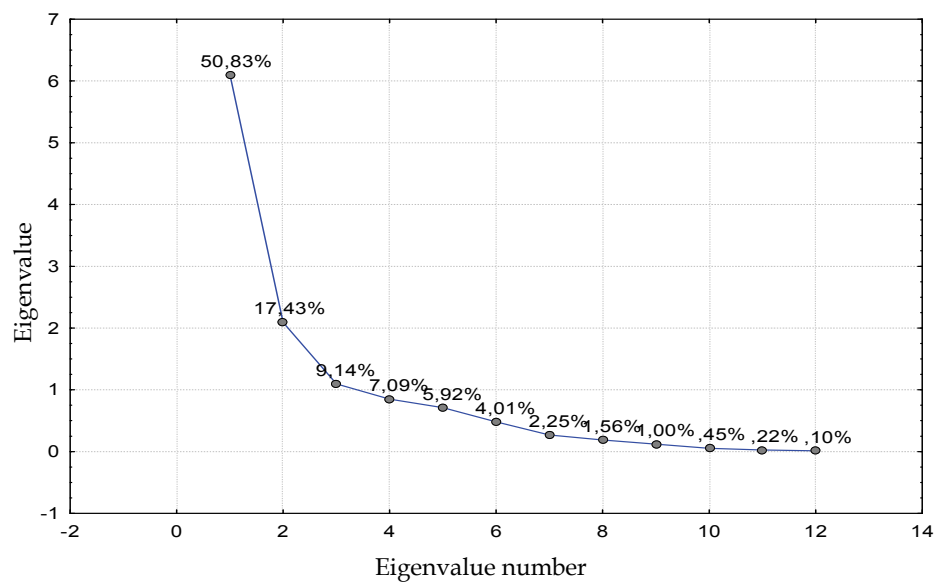

Fig. 5. Screen plot

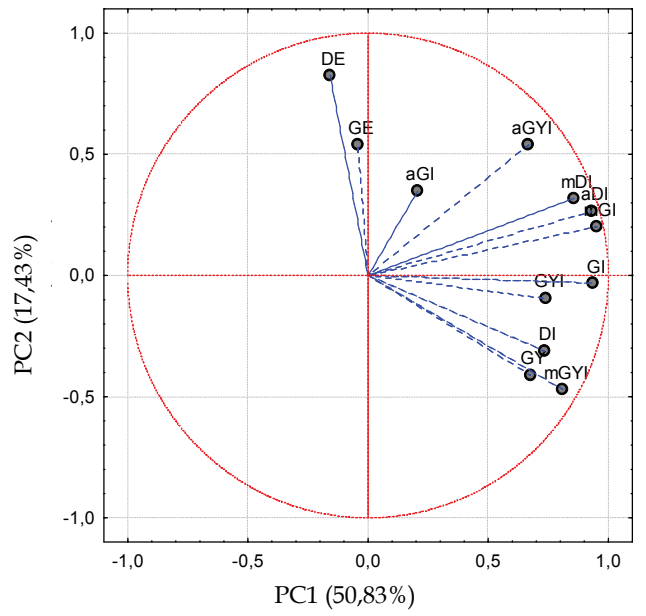

Legend:

DE - daidzein

DI - daidzin

mDI - malonyl daidzin

aDI - acetyl daidzin

GY - glycitein

GYI - glycitin

mGYI - malonyl glycitin

aGYI - acetyl glycitin

GE - genistein

GI - genistin

mGI - malonyl genistin

aGI - acetyl genistin

Fig. 6. Loadings of principal componets

the same group. Variables from the groups (GE, DE) and (mDI, aDI, mGI) are mutually orthogonal; they do not share common information (cosinus of the angle between their vectors is 0 ), whereas variables from the groups (GE, DE) and (DI, GY, mGY) are correlated in opposite directions (angle between their vectors is bigger than $90^{\circ}$ ).

Observing the variables that are most present in pricipal component PC1 and their mutual correlations (Fig. 6), some distinctive parameters of soybean genotypes may be defined. Wang and Murphy (1994) had suggested that, ratios of malonyl daidzin to daidzin and malonyl genistin to genistin in soybeans may be the characteristic of different genotypes, but in the study by $\mathrm{Xu}$ and Chang (2008) it was found that these ratios are not the same in one genotype across different locations. According to the results obtained in this study, ratios of malonyl daidzin to malonyl genistin, genistin to gliticin and malonyl daizdin to acetyl daidzin could be specific characteristics of a particular genotype. 


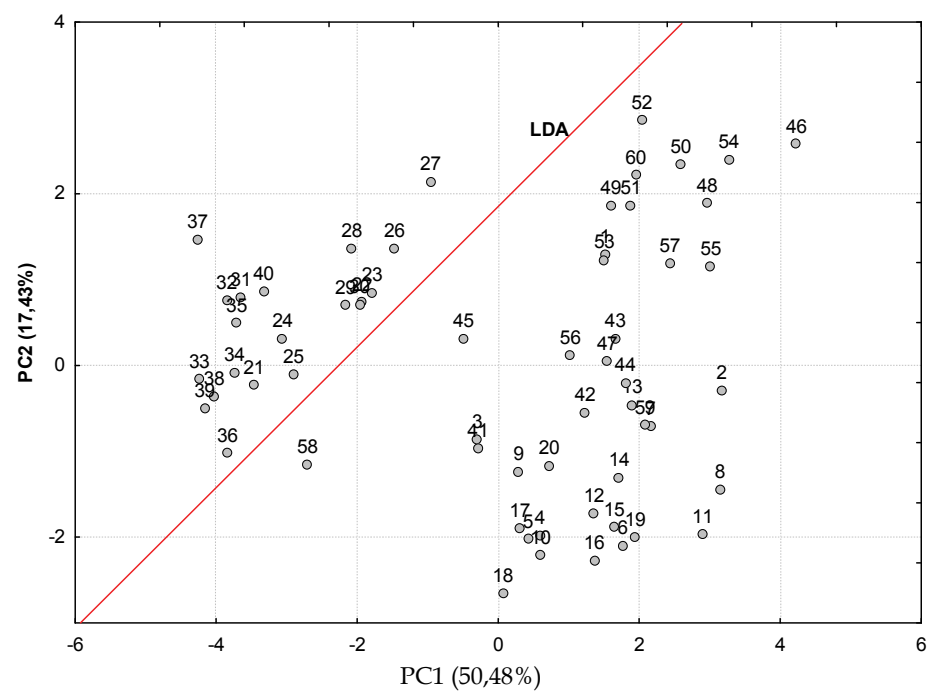

Fig. 7. Principle component scores in the PC1 - PC2 plane

In the score plane of the principal components PC1-PC2, sixty different soybean genotypes have been analysed (Fig. 7). The linear discriminative analysis (LDA) has been applied in vectors space of the principal components and a straight line of the linear discriminant function (red borderline in the graph) has been obtained. This borderline divides the examined sample into two groups: group I (1-20 + 41-60) and group II (21-40). Group II (Fig. 7) contains twenty hybrid soy genotypes grown during 2005, while group I is consisted of forty soybean genotypes, grown during 2004 and 2006. In comparison with the samples from the group I, samples from the group II have considerably lower content of total isoflavones, content of daidzein with its conjugates, content of glycitein with its conjugates and content of genistein with its conjugates. Despite the resemblance in isoflavone composition between parent and hybrid genotypes grown in 2004 and 2005 (Fig. 3), there is a significant $(p<0.05)$ difference in the total and individual isoflavone contents between them $(\mathrm{p}<0.05$, except for acetyl glycitin, genistein and acetyl genistin).

The importance of applied PC1-PC2 model has been established by Hotelling $\mathrm{T}^{2}$ statistics for finding of strong outliers among the analysed objects and D-to-Model diagnostics for finding of moderate outliers. In Fig. 8 (A) it is noticeable that strong outliers do not exist among the examined samples. The samples 37, 50 and 52 are distinguished as moderate outliers, Fig. 8 (B). This confirms that PC1-PC2 model fits well the examined samples, and that the division into groups is the result of differences in the individual isoflavone contents among different genotypes.

Obtained results point out the relevance of the seeding year, as factor that influence isoflavone content in soybeans, which is in the agreement with the previous reports (Wang \& Murphy, 1994; Hoeck et al., 2000; Lee et al., 2003c). On the other hand, the resemblance of isoflavone composition between parents and corresponding hybrids (Fig. 3) determines the crucial influence of genotype in the formation of isoflavone profile in soy. 
(A)

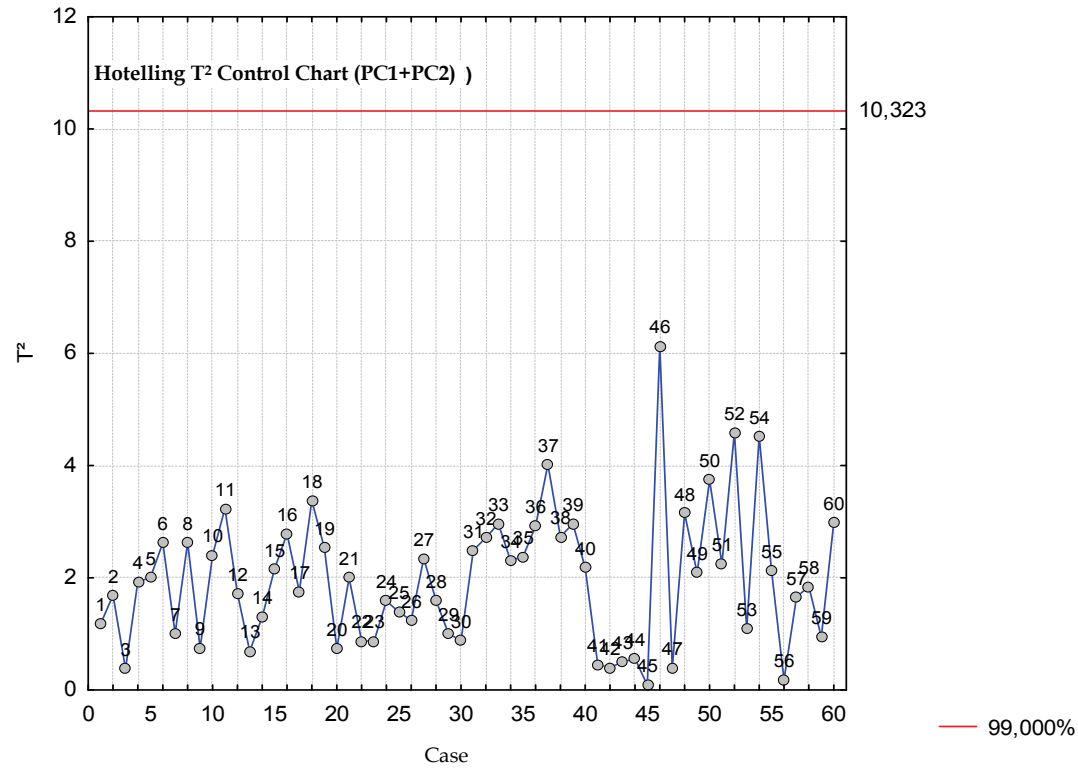

(B)

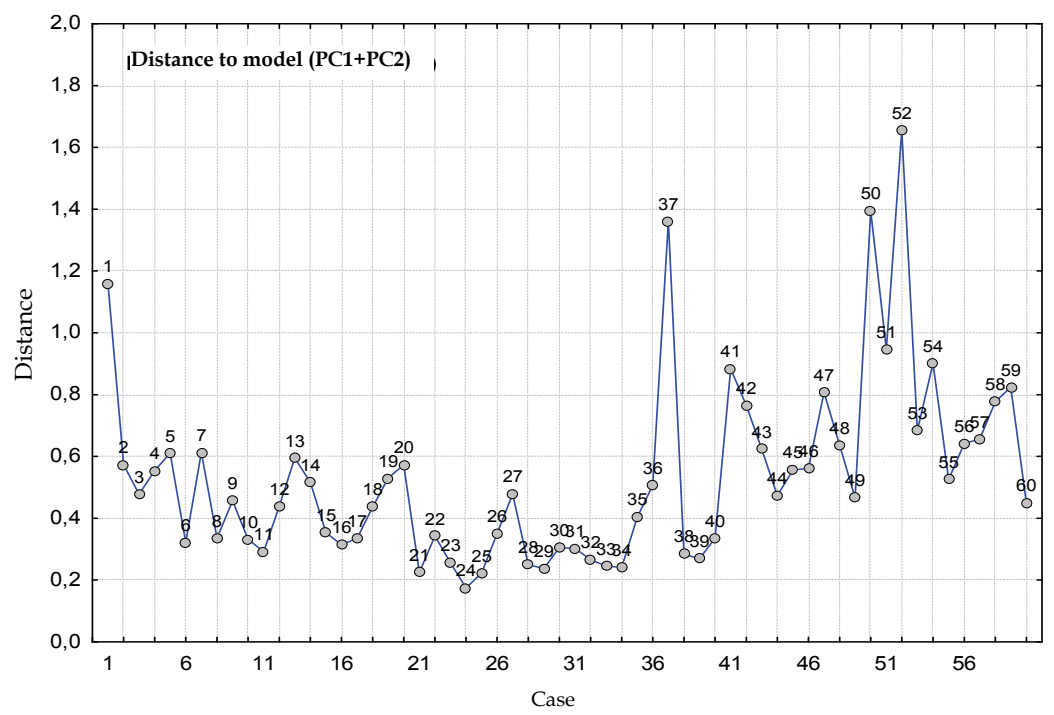

Fig. 8. (A) Hotelling $\mathrm{T}^{2}$ statistics for the model PC1 - PC2 finding strong outliers among the objects). (B) D-to-Model diagnostics of moderate outliers. 


\begin{tabular}{|c|c|c|c|c|c|c|c|c|c|c|c|c|}
\hline No & $\mathrm{DE}$ & DI & $\begin{array}{l}\text { m- } \\
\text { DI }\end{array}$ & $\begin{array}{l}\text { a- } \\
\text { DI }\end{array}$ & GY & GYI & $\begin{array}{c}\text { m- } \\
\text { GYI }\end{array}$ & $\begin{array}{c}\mathrm{a}- \\
\text { GYI }\end{array}$ & GE & GI & $\begin{array}{l}\text { m- } \\
\text { GI }\end{array}$ & $\begin{array}{l}\mathrm{a}- \\
\text { GI }\end{array}$ \\
\hline 1. & 0.02 & 0.58 & 1.76 & 0.27 & 0.03 & 0.15 & 0.47 & 0.07 & 0.07 & 0.47 & 1.82 & 0.01 \\
\hline 2. & 0.02 & 0.69 & 2.00 & 0.37 & 0.04 & 0.15 & 0.54 & 0.09 & 0.02 & 0.66 & 2.32 & 0.00 \\
\hline 3. & 0.02 & 0.45 & 1.16 & 0.21 & 0.03 & 0.13 & 0.42 & 0.07 & 0.01 & 0.35 & 1.18 & 0.00 \\
\hline 4. & 0.00 & 0.42 & 1.13 & 0.24 & 0.03 & 0.20 & 0.62 & 0.07 & 0.01 & 0.36 & 1.29 & 0.00 \\
\hline 5. & 0.00 & 0.45 & 1.17 & 0.21 & 0.02 & 0.29 & 0.57 & 0.06 & 0.01 & 0.35 & 1.18 & 0.00 \\
\hline 6. & 0.00 & 0.71 & 1.91 & 0.25 & 0.03 & 0.19 & 0.59 & 0.07 & 0.00 & 0.48 & 1.55 & 0.00 \\
\hline 7. & 0.02 & 0.88 & 2.20 & 0.27 & 0.02 & 0.15 & 0.61 & 0.09 & 0.01 & 0.53 & 1.62 & 0.00 \\
\hline 8. & 0.00 & 0.77 & 1.78 & 0.35 & 0.03 & 0.20 & 0.57 & 0.09 & 0.01 & 0.72 & 2.02 & 0.00 \\
\hline 9. & 0.00 & 0.53 & 1.15 & 0.23 & 0.02 & 0.13 & 0.38 & 0.08 & 0.01 & 0.50 & 1.47 & 0.00 \\
\hline 10. & 0.00 & 0.53 & 1.21 & 0.22 & 0.02 & 0.23 & 0.58 & 0.06 & 0.00 & 0.44 & 1.26 & 0.00 \\
\hline 11. & 0.00 & 0.82 & 1.83 & 0.31 & 0.03 & 0.19 & 0.65 & 0.07 & 0.01 & 0.69 & 1.96 & 0.00 \\
\hline 12. & 0.01 & 0.83 & 1.68 & 0.24 & 0.03 & 0.15 & 0.51 & 0.06 & 0.01 & 0.55 & 1.41 & 0.00 \\
\hline 13. & 0.03 & 0.85 & 1.81 & 0.28 & 0.02 & 0.15 & 0.50 & 0.07 & 0.01 & 0.71 & 1.69 & 0.00 \\
\hline 14. & 0.02 & 0.87 & 1.78 & 0.27 & 0.03 & 0.16 & 0.52 & 0.06 & 0.01 & 0.59 & 1.47 & 0.00 \\
\hline 15. & 0.01 & 0.76 & 1.55 & 0.28 & 0.03 & 0.21 & 0.50 & 0.04 & 0.01 & 0.63 & 1.59 & 0.00 \\
\hline 16. & 0.00 & 0.71 & 1.39 & 0.27 & 0.02 & 0.22 & 0.57 & 0.04 & 0.01 & 0.63 & 1.44 & 0.00 \\
\hline 17. & 0.00 & 0.62 & 1.13 & 0.22 & 0.02 & 0.15 & 0.42 & 0.05 & 0.01 & 0.61 & 1.29 & 0.00 \\
\hline 18. & 0.00 & 0.63 & 1.14 & 0.19 & 0.03 & 0.21 & 0.42 & 0.02 & 0.01 & 0.52 & 1.12 & 0.00 \\
\hline 19. & 0.01 & 0.91 & 1.68 & 0.26 & 0.03 & 0.21 & 0.47 & 0.04 & 0.01 & 0.71 & 1.58 & 0.00 \\
\hline 20. & 0.02 & 0.80 & 1.26 & 0.23 & 0.02 & 0.16 & 0.36 & 0.05 & 0.01 & 0.71 & 1.32 & 0.00 \\
\hline 21. & 0.02 & 0.21 & 0.78 & 0.13 & 0.00 & 0.09 & 0.14 & 0.04 & 0.01 & 0.12 & 0.72 & 0.00 \\
\hline 22. & 0.02 & 0.35 & 1.10 & 0.22 & 0.00 & 0.10 & 0.15 & 0.07 & 0.01 & 0.23 & 1.15 & 0.00 \\
\hline 23. & 0.03 & 0.35 & 0.93 & 0.23 & 0.00 & 0.11 & 0.16 & 0.07 & 0.02 & 0.31 & 1.13 & 0.00 \\
\hline 24. & 0.03 & 0.24 & 0.70 & 0.13 & 0.00 & 0.12 & 0.18 & 0.05 & 0.02 & 0.18 & 0.76 & 0.00 \\
\hline 25. & 0.02 & 0.30 & 0.74 & 0.16 & 0.00 & 0.09 & 0.12 & 0.05 & 0.01 & 0.24 & 0.79 & 0.00 \\
\hline 26. & 0.03 & 0.37 & 1.07 & 0.21 & 0.00 & 0.11 & 0.14 & 0.09 & 0.03 & 0.33 & 1.27 & 0.00 \\
\hline 27. & 0.05 & 0.52 & 1.37 & 0.24 & 0.00 & 0.11 & 0.14 & 0.09 & 0.03 & 0.37 & 1.27 & 0.00 \\
\hline 28. & 0.04 & 0.39 & 1.09 & 0.19 & 0.00 & 0.11 & 0.14 & 0.07 & 0.03 & 0.27 & 0.97 & 0.00 \\
\hline 29. & 0.03 & 0.40 & 1.06 & 0.16 & 0.00 & 0.11 & 0.14 & 0.07 & 0.02 & 0.27 & 0.94 & 0.00 \\
\hline 30. & 0.03 & 0.46 & 1.15 & 0.18 & 0.00 & 0.09 & 0.15 & 0.07 & 0.02 & 0.29 & 0.96 & 0.00 \\
\hline 31. & 0.04 & 0.29 & 0.85 & 0.12 & 0.00 & 0.05 & 0.08 & 0.04 & 0.02 & 0.17 & 0.68 & 0.00 \\
\hline 32. & 0.04 & 0.25 & 0.78 & 0.11 & 0.00 & 0.06 & 0.08 & 0.04 & 0.02 & 0.15 & 0.58 & 0.00 \\
\hline 33. & 0.03 & 0.22 & 0.56 & 0.05 & 0.00 & 0.07 & 0.10 & 0.03 & 0.01 & 0.15 & 0.54 & 0.00 \\
\hline
\end{tabular}




\begin{tabular}{|c|c|c|c|c|c|c|c|c|c|c|c|c|}
\hline 34. & 0.03 & 0.29 & 0.77 & 0.10 & 0.00 & 0.07 & 0.11 & 0.03 & 0.01 & 0.17 & 0.60 & 0.00 \\
\hline 35. & 0.03 & 0.23 & 0.60 & 0.09 & 0.00 & 0.06 & 0.08 & 0.07 & 0.01 & 0.16 & 0.54 & 0.00 \\
\hline 36. & 0.00 & 0.19 & 0.73 & 0.11 & 0.00 & 0.06 & 0.07 & 0.03 & 0.01 & 0.14 & 0.69 & 0.00 \\
\hline 37. & 0.02 & 0.17 & 0.55 & 0.10 & 0.00 & 0.07 & 0.10 & 0.03 & 0.01 & 0.14 & 0.36 & 0.00 \\
\hline 38. & 0.02 & 0.24 & 0.72 & 0.11 & 0.00 & 0.08 & 0.09 & 0.03 & 0.01 & 0.01 & 0.63 & 0.00 \\
\hline 39. & 0.02 & 0.24 & 0.59 & 0.10 & 0.00 & 0.05 & 0.06 & 0.02 & 0.01 & 0.17 & 0.56 & 0.00 \\
\hline 40. & 0.04 & 0.34 & 0.69 & 0.12 & 0.00 & 0.08 & 0.07 & 0.04 & 0.03 & 0.28 & 0.72 & 0.00 \\
\hline 41. & 0.02 & 0.30 & 1.37 & 0.22 & 0.01 & 0.34 & 0.39 & 0.03 & 0.01 & 0.39 & 1.16 & 0.00 \\
\hline 42. & 0.00 & 0.59 & 1.36 & 0.32 & 0.00 & 0.20 & 0.29 & 0.09 & 0.00 & 0.63 & 1.94 & 0.00 \\
\hline 43. & 0.02 & 0.45 & 2.48 & 0.34 & 0.00 & 0.23 & 0.47 & 0.07 & 0.01 & 0.55 & 1.90 & 0.00 \\
\hline 44. & 0.02 & 0.46 & 2.20 & 0.33 & 0.03 & 0.24 & 0.36 & 0.07 & 0.01 & 0.51 & 1.82 & 0.00 \\
\hline 45. & 0.02 & 0.23 & 1.20 & 0.27 & 0.00 & 0.19 & 0.36 & 0.08 & 0.01 & 0.36 & 1.48 & 0.00 \\
\hline 46. & 0.05 & 0.63 & 3.32 & 0.45 & 0.02 & 0.24 & 0.44 & 0.12 & 0.03 & 0.71 & 2.49 & 0.00 \\
\hline 47. & 0.00 & 0.39 & 1.78 & 0.33 & 0.00 & 0.21 & 0.40 & 0.11 & 0.01 & 0.59 & 1.92 & 0.00 \\
\hline 48. & 0.04 & 0.66 & 2.90 & 0.36 & 0.00 & 0.25 & 0.41 & 0.11 & 0.02 & 0.68 & 2.16 & 0.00 \\
\hline 49. & 0.04 & 0.59 & 2.23 & 0.32 & 0.00 & 0.20 & 0. & 0.10 & 0.03 & 0.64 & 1.82 & 0.00 \\
\hline 50. & 0.02 & 0.58 & 3.21 & 0.37 & 0.02 & 0.21 & 0.38 & 0.08 & 0.11 & 0.51 & 2.07 & 0.00 \\
\hline 51. & 0.02 & 0.32 & 1.42 & 0.39 & 0.02 & 0.18 & 0.25 & 0.11 & 0.02 & 0.65 & 2.06 & 0.01 \\
\hline 52. & 0.04 & 0.46 & 1.79 & 0.32 & 0.03 & 0.23 & 0.27 & 0.09 & 0.03 & 0.59 & 1.68 & 0.02 \\
\hline 53. & 0.04 & 0.68 & 2.54 & 0.28 & 0.00 & 0.26 & 0.33 & 0.08 & 0.02 & 0.57 & 1.56 & 0.00 \\
\hline 54. & 0.03 & 0.41 & 1.85 & 0.47 & 0.03 & 0.19 & 0.27 & 0.12 & 0.02 & 0.72 & 2.42 & 0.01 \\
\hline 55. & 0.03 & 0.50 & 2.09 & 0.41 & 0.02 & 0.21 & 0.33 & 0.11 & 0.02 & 0.74 & 2.19 & 0.00 \\
\hline 56. & 0.02 & 0.44 & 2.17 & 0.28 & 0.00 & 0.27 & 0.47 & 0.08 & 0.01 & 0.43 & 1.51 & 0.00 \\
\hline 57. & 0.03 & 0.50 & 2.55 & 0.36 & 0.00 & 0.30 & 0.43 & 0.09 & 0.02 & 0.61 & 2.06 & 0.00 \\
\hline 58. & 0.02 & 0.23 & 0.76 & 0.14 & 0.00 & 0.25 & 0.25 & 0.00 & 0.01 & 0.25 & 0.73 & 0.00 \\
\hline 59. & 0.02 & 0.28 & 1.67 & 0.34 & 0.03 & 0.32 & 0.62 & 0.07 & 0.02 & 0.47 & 1.89 & 0.00 \\
\hline 60. & 0.05 & 0.50 & 2.37 & 0.35 & 0.01 & 0.21 & 0.36 & 0.10 & 0.03 & 0.62 & 1.94 & 0.00 \\
\hline
\end{tabular}

Abbreviations: No-number of sample, DE-daidzein, DI-daidzin, mDI-malonyl daidzin, aDI-acetyl daidzin, GY-glycitein, GYI-glycitin, mGYI-malonyl glycitin, aGYI-acetyl glycitin, GE-genistein, GIgenistin, mGE-malonyl genistin; aGE-acetyl genistin

Table 2. Data matrix

\section{Conclusion}

The content of the twelve isoflavones in sixty genotypes of soybean, planted during three different years, has been analysed using the principal component method, with the aim to examine if there is any correlation among different isoflavone forms in soybeans and to 
investigate the relations between different soybean genotypes, according to their isoflavone profiles. The obtained results show that malonylglucoside and glucoside isoflavone forms determine to a great extent the isoflavone composition in soy. The mutual position of the variables in the plane of PC1 and PC2 loading vectors suggest that ratios of malonyl daidzin to malonyl genistin, genistin to glycitin and malonyl daizdin to acetyl daidzin could be specific characteristics of a particular soybean genotype. The division of the examined genotypes into two groups according to the PC1-PC2 model has showed that cultivation year significantly influences the total and the individual isoflavone contents in soybeans.

\section{Acknowledgement}

This work is part of the project of Ministry of Science and Technical Development, Republic of Serbia.

\section{References}

Adlercreutz, H. \& Mazur, W. (1997). Phyto-oestrogens and Western diseases. Annals of Medicine, 29.,2., (April, 1997) 95-120, ISSN: 1365-2060

Akiyama, T.; Ishida, J.; Nakagawa, S.; Ogawara, H.; Watanabe, S.; Itoh, N.; Shibuya, M.; Fukami, Y. (1987). Genistein, a specific inhibitor of tyrosine-specific protein kinases. The Journal of biological chemistry, 262., 12., (April, 1987) 5592-5595, ISSN: 1083-351X

Anderson, R.L. \& Wolf, W.J. (1995). Compositional changes in trypsin inhibitors, phytic acid, saponins and isoflavones related to soybean processing. The Journal of Nutrition, 125., 3 suppl., (March, 1995) 581S-588S, ISSN: 1541-6100

Atanacković, M.; Posa, M.; Heinle, H.; Gojković-Bukarica, L. \& Cvejić, J. (2009). Solubilization of resveratrol in micellar solutions of different bile acids. Colloids and Surfaces. B, Biointerfaces, 72., 1., (August 2009) 148-154, ISSN: 1873-4367.

Barnes, S.; Peterson, C.; Grubbs, K. \& Setchell, K. (1994). Potential role of dietary isoflavones in the prevention of cancer. Advances in Experimental Medicine Biology, 354, 135-147, ISSN: 0065-2598

Barnes, S.; Boersma, B.; Patel, R.; Kirk, M.; Darley-Usmar, VM.; Kim, H.; Xu, J. (2000). Isoflavonoids and chronic disease: mechanisms of action. Biofactors, 12., 1-4., 209215, ISSN: 1872-8081

Bickoff, E.M.; Livingston, A.L.; Henderson, A.P. \& Booth, A.N. (1962). Forage estrogens, relative potencies of several estrogen-like compounds found in forages. Journal of Agricultural and Food Chemistry, 10., 5., (May, 1962) 410-412, ISSN: 1520-5118

Biggers, J.D. \& Curnow, D.H. (1954). The oestrogenic activity of genistein. Biochemical Journal, 58., 2., (October, 1952) 278-282,

Branham, W.S.; Dial, S.L.; Moland, C.L.; Hass, B.S.; Blair, R.M.; Fang, H.; Shi, L.; Tong, W.; Perkins, R.G. \& Sheehan, D.M. (2002). Phytoestrogens and mycoestrogens bind to the rat uterine estrogen receptor. The Journal of Nutrition, 132., 4., (April, 2002) 648664, ISSN: 1541-6100

Brerton, R.G. (2003). Chemometrics: Data Analysis for the Laboratory and Chemical Plant, John Wiley \& Sons Ltd, ISBN: 978-0-471-48978-8, Chichester.

Cassidy, A.; Hanley, B. \& Lamuela-Raventos, R.M. (2000). Isoflavones, lignans and stilbenesorigins, metabolism and potential importance to human health. Journal of the Science of Food and Agriculture. 80., 7., (May, 2000) 1044-1062, ISSN: 1097-0010 
Cederroth, R. \& Nef, S. (2009). Soy, phytoestrogens and metabolism: A review. Molecular and Cellular Endocrinology, 304., (May, 2009) 30-42, ISSN: 1872-8057

Cesar I.C.; Braga, F.C.; Soares, C.D.V.; Nunan, E.A.; Pianetti, G.E.; Condessa, F.A.; Barbosa, T.A.F.; Campos, L.M.M. (2006). Development and validation of a RP-HPLC method for quantification of isoflavone aglycones in hydrolyzed soy dry extracts. Journal of Chromatography B, 836., 1-2., (May, 2006) 74-78, ISSN: 1570-0232

Ćeran V.; Popović, J.; Cvejić, J. \& Atanacković, M. (2007). Soybean extract as antioxidant active and dietary supplement ingredient. Proceedings of Fourth Congress of Pharmacy of Macedonia with International Participation, pp. 316-316, Ohrid, September, 2007, ISSN: 1409-8695, Macedonian Pharmaceutical Bulletin, Makedonsko Farmacevtsko drustvo, Skopje.

Chiechi, L.M.; Secreto, G.; Vimercati, A.; Greco, P.; Venturelli, E.; Pansini, F.; Fanelli, M.; Loizzi, P.; Selvaggi. L. (2002). The effects of a soy rich diet on serum lipids: the Menfis randomized trial. Maturitas, 41., 2., (February, 2002) 97-104, ISSN: 0378-5122

Chung, H.; Hogan, S.; Zhang, L.; Rainey, K. \& Zhou, K. (2008). Characterisation and comparison of antioxidant properties and bioactive components of Virginia Soybeans. Journal of Agricultural and Food Chemistry. 56., 23., (November, 2008) 11515-11519, ISSN: 1520-5118

Crouse, J.R.; Morgan, T.M.; Terry, J.G.; Ellis, J.E.; Vitolins, M.Z. \& Burke, G.L. (1999). A randomized trial comparing the effect of casein with that of soy protein containing varying amounts of isoflavones on plasma concentrations of lipids and lipoproteins. Archives of internal medicine., 159., 17., (September, 1999) 2070-2076, ISNN: 1539-3704

Cvejić, J.; Malenčić, Đ.; Tepavčević, V.; Poša, M. \& Miladinović, J. (2009). Determination of phytoestrogen composition in soybean cultivars in Serbia. Natural Product Communications, 4., 8., (August, 2009) 1069-1074, ISNN: 1555-9475

Day, A.J.; Dupont M.S.; Ridley, S.; Rhodes, M.J.C.; Morgan M.R.A. \& Wiliamsosm, G. (1998). Deglycosylation of flavonoid and isoflavonoid glycosides by human small intestine and liver beta-glucosidase activity. FEBS Letters, 436., 1., (September, 1998) 71-75, ISSN: 0014-5793

Devi, M.K.A.; Gondi, M.; Sakthivelu, G.; Giridhar, P.; Rajasekaran, T. \& Ravishankar, G.A. (2009). Functional attributes of soybean seeds and products, with reference to isoflavone content and antioxidant activity. Food Chemistry, 114., 3., (June, 2009) 771-776, ISSN: 1520-5118

Diel, P.; Scukz, T.; Smolnikar, K.; Strunck, K.; Vollmer, G. \& Michna, H. (2000). Ability of xeno- and phytoestrogens to modulate expression of estrogen-sensitive genes in rat uterus: estrogenicity profiles and uterotropic activity. Journal of steroid biochemistry and molecular biology, 73., 1-2., (May, 2000) 1-10, ISSN: 0960-0760

Diel, P.; Scmidt, S.; Vollmer, G.; Janning, P.; Upmeier, A.; Michns, H.; Bolt, H.M. \& Degen, G.H. (2004). Comparative responses of three rat strains (DA/Han, Sprague-Dawley and Wistar) to treatment with environmental estrogens. Archives of toxicology, 78., 4., (April, 2004) 183-193, ISSN: 1432-0738

Djuric, Z.; Chen, G.; Doerge, D.R.; Heilbrun, L.K. \& Kucuk, O. (2001). Effect of soy isoflavone supplementation on markers of oxidative stress in men and women. Cancer Letters, 172.,1., (October, 2001) 1-6, ISSN: 0304-3835 
Genovese, M.I.; Hassimotto, N.M.A. \& Lajolo, F.M. (2005). Isoflavone profile and antioxidant activity in Brazilian soybean varieties. Food Science and Technology International, 11., 3., (June, 2005) 205-211, ISSN: 1532-1738

Genovese, M.I.; Davila, J.; Lajolo, F.M. (2006). Isoflavones in processed soybean products from Ecuador. Brazilian Archives of Biology and Technology, 49., 5., (September, 2006) 853-859, ISSN: 1678-4324

Hoeck, J.A.; Fehr, W.R.; Murphy, P.A. \& Welke, G.A. (2000). Influence of genotype and environment on isoflavone contents of soybean. Crop Science, 40., 1., 48-51, ISSN: 0011-183X

Ikeda, Y.; Iki, M.; Morita, A.; Kajita, E.; Kagamimori, S.; Kagawa, Y. \& Yoneshima, H. (2006). Intake of fermented soybeans, natto, is associated with reduced bone loss in postmenopausal women: Japanese Population-Based Osteoporosis (JPOS) Study. The Journal of Nutrition, 136., 5., (May, 2006) 1323-1328, ISSN: 1541-6100

Kupier, G.G.; Carlsson, B.; Grandien, K.; Enmark, E.; Haggblad, J.; Nilsson, S. \& Gustafsson, J.A. (1997). Comparison of the ligand binding specificity and transcript tissue distribution od estrogen receptors alpha and beta. Endocrinology, 138., 3., (March, 1997) 863-870, ISSN: $1945-7170$

Kuiper, G.G.; Lemmen, J.G.; Carlsson, B.; Corton, J.C.; Safe, S.H.; Saag, P.T.; Burg, B. \& Gustafsson, J.A. (1998). Interaction of estrogenic chemicals and phytoestogens with estrogen receptor beta. Endocrinology, 139., 10., (October, 1998) 4252-4263. ISSN: $1945-7170$

Lee, S.J.; Ahn, J.K.; Kim, S.H.; Kim, J.T.; Han, S.J.; Jung. M.Y. \& Chung, I.M. (2003a). Variation in isoflavones of soybean cultivars with location and storage duration. Journal of Agricultural and Food Chemistry, 51., 11., (May, 2003) 3382-3389, ISSN: $1520-5118$

Lee, M.M.; Gomez, S.L.; Chang, J.S.; Wey, M. \& Wang R.T. (2003b). Soy and isoflavone consumption in relation to prostate cancer risk in China. Cancer Epidemiology, Biomarkers \& Prevention. 12., 7., (July, 2003) 665-668, ISSN: 1538-7755

Lee, S.J.; Yan, W.; Ahn, J.K. \& Chung, I.M. (2003c). Effects of year, site, genotype and their interactions on various soybean isoflavones. Field Crops Research, 81., 2-3., 181-192, ISSN: 0378-4290

Lee, J.H.; Renita, M.; Fioritto, R.J.; Martin, S.K.; Schwartz, S.J. \& Vodovotz, Y. (2004). Isoflavone Characterisation and Antioxidant Activity of Ohio Soybeans. Journal of Agricultural and Food Chemistry, 52., 9., (April, 2004) 2647-2651, ISSN: 1520-5118

Lee, Y.W.; Kim, J.D.; Zheng, J. \& Row, K.H. (2007). Comparisons of isoflavones from Korean and Chinese soybean and processed products. Biochemical Engineering Journal, 36., 1., (August, 2007) 49-53, ISSN: 1369-703X

Malenčić, Đ.; Cvejić, J.; Ćeran-Tepavčević, V. \& Popović, M. (2008). Total polyphenols and phytoestrogens concentration and DPPH-scavenging activity in soybean of different origin, Proceedings of 7 th Joint Meeting of AFERP, ASP, GA, PSE \& SIF, pp ISSN: 1177-1177, 00320943, Athens, Greece, August, 2008, Planta Medica, Georg Thieme Verlag KG, Stuttgart.

Moriguchi, E.H.; Moriguchi, Y. \& Yamori, Y. (2004). Impact of diet on the cardiovascular risk profile of Japanese immigrants living in brasil: Contributions of world health organization cardiac and Monalisa studies. Clinical and Experimental Pharmacology and Physiology 31., (December, 2004) 5S-7S, ISSN: 1440-1681 
Nelson, H.D.; Vesco, K.K.; Haney, E.; Rongwei Fu, R.; Nedrow, A.; Miller, J.; Nicolaidis, C.; Walker, M.; Humphrey, L.; (2006). Nonhormonal therapies for menopausal hot flashes: systematic review and meta-analysis. JAMA. 295., 17., (May, 2006) 20572071, ISSN: 1538-3598

Philips, K.M.; Ruggio, D.M.; Toivo, J.I.; Swank, M.A. \& Simpkins, A.H. (2002). Free and esterified sterol composition of edible oils and fats. Journal of Food Composition and Analysis. 15., 2., (April, 2002) 123-142, ISSN: 0889-1575

Potter, S.M.; Baum, J.A. \& Teng, H. (1998). Soy protein and isoflavones. Their effects on blood lipids and bone density in postmenopausal women. American Journal of Clinical Nutrition, 68, 6 supl., (December, 1998) 1375S-1379S, ISSN: 1938-3207

Poša, M. (2010). Osnovne metode u hemometriji, 70-87, Faculty of Medicine, University of Novi Sad, 9788679940124, Novi Sad.

Ribeiro, M.L.L.; Mandarino, J.M.G.; Carrao-Panizzi, M.C.; Oliviera, M.C.N.; Campo, C.B.H. Nepomuceno, A.L. \& Ida E.I. (2007). Isoflavone content and $\beta$-glucosidase activity in soybean cultivars of different maturity groups. Journal of Food Composition and Analysis. 20., 1., (February, 2007) 19-24, ISSN: 0889-1575

Romani, A.; Vignolini, P.; Galardi, C.; Aroldi, C.; Vazzana C. \& Heimler, D. (2003). Polyphenolic content in different plant parts of soy cultivars grown under natural conditions. Journal of Agricultural and Food Chemistry, 51., 18., (July, 2003) 5301-5306, ISSN: $1520-5118$

Ruiz-Larrea, M.B.; Mohan, A.R.; Paganga, G.; Miller, N.J.; Bolwell, G.P. \& Rice-Evans, C.A. (1997) Antioxidant Activity of Phytoestrogenic Isoflavones. Free Radical Research 26., 1., (January, 1997) 63-70, ISSN: 1071-5762

Sarkar, F.H. \& Li, Y. (2003). Soy isoflavones and cancer prevention. Cancer Investigation, 21., 5., 744-757, ISSN: 1532-4192

Setchell, K.D.R.; Brown, N.M. \& Lydeking-Olsen, E. (2002). The clinical importance of the metabolite equol-a clue to the effectiveness of soy and its isoflavones. The Journal of Nutrition. 132., 12., (December, 2002) 3577-3584, ISSN: 1541-6100

Scheiber, M.D.; Liu, J.H.; Subbiah, M.T.; Rebar, R.W.; Setchell, K.D. (2001). Dietary inclusion of whole soy foods results in significant reductions in clinical risk factors for osteoporosis and cardiovascular disease in normal postmenopausal women. Menopause, 8., 5., (sept-oct, 2001) 384-392, ISSN: 1530-0374

Simons, A.L.; Renouf, M.; Hendrich, S. \& Murphy, P.A. (2005). Metabolism of Glycitein (7,4'Dihydroxy-6-methoxy-isoflavone) by Human Gut Microflora. Journal of Agricultural and Food Chemistry, 53., 8., (October, 2005) 8519-8525, ISSN: 1520-5118

Song, T.T.; Hendrich, S. \& Murphy, P.A. (1999). Estrogenic activity of glycitein, a soy isoflavone. Journal of Agricultural and Food Chemistry, 47., 4., (April, 1999) 1607-1610, ISSN: $1520-5118$

Szepesvári, P. (2001). Főkomponens-elemzés, In: Sokváltozos adatelemzés (kemometria), Horvai, Gy. (Ed.), 84-95, Nemzeti Tankönyvkiadó, 963192114 X, Budapest.

Tepavčević, V.; Cvejić, J.; Počuča, M. \& Popović, J. (2008). Characterisation and Dissolution Properties of Soy isoflavones form Commercial Capsule Formulation. Proceedings of $7^{\text {th }}$ Xenobiotics Metabolism and Toxicity Workshop of Balkan Countries, pp. 10-20, Novi Sad, Serbia, June, 2008, European Journal of Drug Metabolism and Pharmacokinetics, Medecine et Hygiene, Geneva. 
Tepavčević, V.; Atanacković, M.; Miladinović, J.; Malenčić, Đ.; Popović, J. \& Cvejić, J. (2010). Isoflavone composition, total polyphenolic content, and antioxidant activity in soybeans of different origin. Journal of Medicinal Food, 13., 3., (Jun, 2010) 657-664, ISSN: $1557-7600$

Tsukamoto, C.; Shimada, S.; Igita, K.; Kudou, S.; Kokubun, M.; Okubo, K. \& Kitamura, K. (1995). Factors affecting isoflavone content in soybean seeds: Changes in isoflavones, saponins, and composition of fatty acids at different temperatures during seed development. Journal of Agricultural and Food Chemistry, 43., 5., (May, 1995) 1184-1192, ISSN: 1520-5118

Wang, H.J. \& Murphy, P.A. (1994). Isoflavone composition of American and Japanese soybeans in Iowa: effects of variety crop, year and location. Journal of Agricultural and Food Chemistry, 42., 8., (August, 1994) 1674-1677, ISSN: 1520-5118

Whitehead, S.A.; Cross, J.E.; Burden, C. \& Lacey, M. (2002). Acute and chronic effects of genistein, tyrphostin and lavendustin A on steroid synthesis in luteinized human granulosa cells. HumanReproduction, 17., 3., (March, 2002) 589-594. ISSN: 1460-2350

Wiseman, H.; O'Reilly, J.D.; Adlercreutz, H.; Mallet, A.I.; Bowey. E.A.; Rowland, I.R.; Sanders, T.A.; (2000). Isoflavone phytoestrogens consumed in soy decrease $F(2)$ isoprostane concentrations and increase resistance of low-density lipoprotein to oxidation in humans. American Journal of Clinical Nutrition, 72., 2., (August, 2000) 395-400, ISSN: 1938-3207

Wold, H. (1975). Soft Modeling by Latent Variables: the Nonlinear Iterative Partial Least Squares Approach. In: Perspectives in Probability and Statistics, Gani, J. (Ed.), 520-540, Academic Press, 0122744500, London.

Wu, A.H.; Yu, M.C.; Tseng, C.C. \& Pike, MC. (2008). Epidemiology of soy exposures and breast cancer risk. British Journal of Cancer, 98., 1., (January, 2008) 9-14, ISSN: 00070920

$\mathrm{Xu}$, B. \& Chang, S.K. (2008) Characterization of phenolic substances and antioxidant properties of food soybeans grown in the North Dakota-Minnesota Region. Journal of Agricultural and Food Chemistry. 56., 19., (October,2008) 9102-9113, ISSN: 15205118 


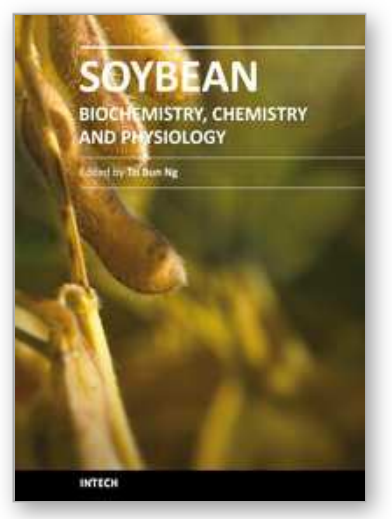

\section{Soybean - Biochemistry, Chemistry and Physiology \\ Edited by Prof. Tzi-Bun Ng}

ISBN 978-953-307-219-7

Hard cover, 642 pages

Publisher InTech

Published online 26, April, 2011

Published in print edition April, 2011

Soybean is an agricultural crop of tremendous economic importance. Soybean and food items derived from it form dietary components of numerous people, especially those living in the Orient. The health benefits of soybean have attracted the attention of nutritionists as well as common people.

\section{How to reference}

In order to correctly reference this scholarly work, feel free to copy and paste the following:

Vesna Tepavcevic, Jelena Cvejic, Mihalj Posa and Jovan Popovic (2011). Isoflavone Content and Composition in Soybean, Soybean - Biochemistry, Chemistry and Physiology, Prof. Tzi-Bun Ng (Ed.), ISBN: 978-953-307219-7, InTech, Available from: http://www.intechopen.com/books/soybean-biochemistry-chemistry-andphysiology/isoflavone-content-and-composition-in-soybean

\section{INTECH}

open science | open minds

\section{InTech Europe}

University Campus STeP Ri

Slavka Krautzeka 83/A

51000 Rijeka, Croatia

Phone: +385 (51) 770447

Fax: +385 (51) 686166

www.intechopen.com

\section{InTech China}

Unit 405, Office Block, Hotel Equatorial Shanghai

No.65, Yan An Road (West), Shanghai, 200040, China 中国上海市延安西路65号上海国际贵都大饭店办公楼 405 单元

Phone: +86-21-62489820

Fax: $+86-21-62489821$ 
(C) 2011 The Author(s). Licensee IntechOpen. This chapter is distributed under the terms of the Creative Commons Attribution-NonCommercialShareAlike-3.0 License, which permits use, distribution and reproduction for non-commercial purposes, provided the original is properly cited and derivative works building on this content are distributed under the same license. 